\title{
Observations of the Palest Morph of the Greater Spotted Eagle in Southern Siberia, Russia
}

\section{РЕГИСТРАЦИИ ПОДОРЛИКОВ СВЕТЛОЙ МОРФЫ В ЮЖНОЙ СИБИРИ, РОССИЯ}

\author{
Karyakin I.V., Serova S.V. (Center of Field Studies, N. Novgorod, Russia) \\ Bachtin R.F., Vazhov S.V. (Shukshin Altai State Academy of Education, Biysk, Russia) \\ Nikolenko E.G., Shnayder E.P., Shtol D.A. (Siberian Environmental Center, Novosibirsk, \\ Russia) \\ Bekmansurov R.H. (Elabuga brunch of Kazan Federal University, Elabuga, Russia) \\ Baydukov S.N. (Altaipriroda, Barnaul, Russia) \\ Pisarevskiy S.V. (Novosibirsk branch, Russian Bird Conservation Union, Novosibirsk, \\ Russia) \\ Ebel A. L. (Altai branch, Russian Bird Conservation Union, Barnaul, Russia) \\ Карякин И.В., Серова С.В. (Центр полевых исследований, Н. Новгород, Россия) \\ Бахтин Р.Ф., Важов С.В. (Алтайская государственная академия образования \\ им. В.М. Шукшина, Бийск, Россия) \\ Николенко Э.Г., Шнайдер Е.П., Штоль Д.А. (МБОО «Сибирский экологический \\ центр», Новосибирск, Россия) \\ Бекмансуров Р.Х. (Елабужский институт Казанского Федерального университета, \\ Елабуга, Россия) \\ Байдуков С.Н. (Алтайприрода, Барнаул, Россия) \\ Писаревский С.В. (Новосибирское отделение Союза охраны птиц России, \\ Новосибирск, Россия) \\ Эбель А.Л. (Алтайское отделение Союза охраны птиц России, Барнаул, Россия)
}

\section{Контакт: \\ Игорь Карякин \\ Центр полевых иссле-

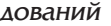 \\ 603109, Россия, \\ Нижний Новгород, \\ ул. Нижегородская, 3-29 \\ тел.: +7962 5083037 \\ ikar_research@mail.ru \\ Роман Бахтин \\ тел.: +79059803139 \\ al.raptors@yandex.ru

\author{
Сергей Важов \\ тел.: +79635348107 \\ aquila-altai@mail.ru
}

Анна Барашкова

yazula@yandex.ru

Эльвира Николенко elvira_nikolenko@mail.ru

Елена Шнайдер equ001@gmail.com

Амитрий Штоль d.shtol@gmail.com

Ринур Бекмансуров rinur@yandex.ru
У большого подорлика (Aquila clanga) в ювенильном наряде сушествует светлая морсра, называемая fulvescens. Её название прижилось в научной митературе от прежнего видового названия подобных птиц Aquila fulvescens Gray, 1883 (см. Штегман, 1938).

Mopdpa fulvescens - вариация окраски большого подорлика в ювенильном наряле, у которой типичные бурые тона кроюших заменены золотисто-жёлтыми с тёмными наствольями на голове и зобе и с тёмными центрами больших кроюших и занними плечевыми, при этом махи и рули остаются характерными мия вида - тёмно-бурыми (Аементьев, 1951; Forsman, 1999). Эти особи связаны с "типичными" подорликами полным рялом переходов и могут быть встречены в одном и том же выводке с птицами обычной окраски. По Аанным Г.П. Аементьева (1951) геограсически распространение светлой вариации не локамизовано, хотя Аик Форсман (Forsman, 1999) пишет, что светлые птицы встречаются чаше на востоке ареала. В СССР светлые подорлики в первой полови-
Juvenile birds of Greater Spotted Eagles (GSE) very seldom occur in a palest variation fulvescens. Previously this individuals were considered as a separate species Aquila fulvescens Gray, 1883.

This variation is defined by golden-yellow body feathers instead of brown, with dark centres on head and throat, on greater coverts and rear scapulars; and with brown flight and tail feathers (Dementyev, 1951; Forsman, 1999). Individuals of this variation could be found in one brood with typical birds. Dementyev (1951) considered that geographical distribution of fulvescens morph is not localized. However, Dick Forsman (1999) wrote that palest form is more common in the eastern part of distribution area of GSE. In the first half of XX century, GSEs of var. fulvescens were bagged by hunters in 14 regions of USSR, with 6 of them located in Siberia. In Altai-Sayan Ecoregion pale GSE were all found in Minusinsk depression (Dementyev, 1951).

Today Russian authors still mentioned pale morphs of GSE only for Minusinsk depression. But no data is published about occupied nests with fledglings and distribution 
Сергей Писаревский bluesrock@yandex.ru

Аиексей Эбель alexey_ebel@mail.ru

\section{Contact:}

Igor Karyakin

Center of Field Studies

Nizhegorodskaya str.,

3-29,

Nizhniy Novgorod

Russia, 603109

tel.: +7962 5083037

ikar_research@mail.ru

Roman Bachtin

tel.: +79059803139

al.raptors@yandex.ru

Sergey Vazhov

tel.: +79635348107

aquila-altai@mail.ru

Elvira Nikolenko

elvira_nikolenko@mail.ru

Elena Shnayder equ001@gmail.com

Dmitry Shtol

d.shtol@gmail.com

Rinur Bekmansurov rinur@yandex.ru

Sergey Pisarevskiy bluesrock@yandex.ru

Aleksey Ebel alexey_ebel@mail.ru
Размножаюшаяся пара больших подорликов светлой морфы (Aquila clanga m. fulvescens): самец (вверху) и самка (внизу). Республика Хакасия, июнь 2004 г. Фото И. Карякина.

Breeding pair of the Greater Spotted Eagle with both mates of palest morph (Aquila clanga $\mathrm{m}$. fulvescens): male (upper) and female (bottom). Republic of Khakassia, Russia. June 2004. Photos by I. Karyakin.

не XX столетия добывались в 14 районах, причём 6 из них относятся к Сибири. В Аһтае-Саянском регионе светлых подорликов добываии в Минусинской котловине: в окрестностях Минусинска и в Абаканской степи (Аементьев, 1951).

В современной русскоязычной митературе инсормация о встречах подорликов морсы fulvescens имеется лишь Аля Минусинской котловины, но описаний находок гнёзА с птенцами и какой-либо статистики о встречаемости этой морсы в гнездовом ареале большого подорлика нет вообше. $\triangle$ анным сообшением хочется закрыть этот пробел.

В Минусинской котловине в настояшее время известны регистрации 7 подорликов морсы fulvescens на 4-х участках в бассейне Чулыма. ОАиночная птица встречена в Аолине р. Белый Июс (Хакасия) близ А. Кобяково 24 мая 2000 г. Позже здесь же и на Чёрном Июсе близ м. Подкамень были выявлены 2 гнездовых участка подорликов с пуховыми птенцами, типичными мяя вида, на которых светлые птицы в различных сталиях пост-ювенильной миньки наблюдамись 24 мая 2002 г. и в июне 2004 г. (Карякин, 2005; 2008). Ещё одна светлая птица встречена на р. Чулым ниже с. Копьево (граница Хакасии и Красноярского края) 2 июля 2004 г. и также одна светлая

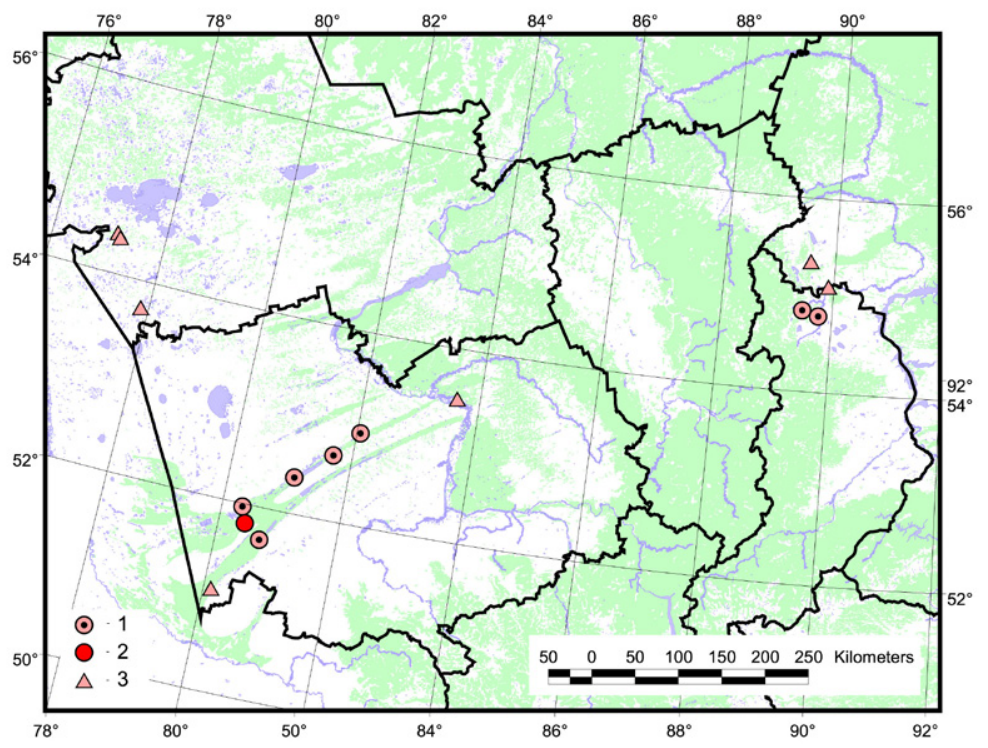

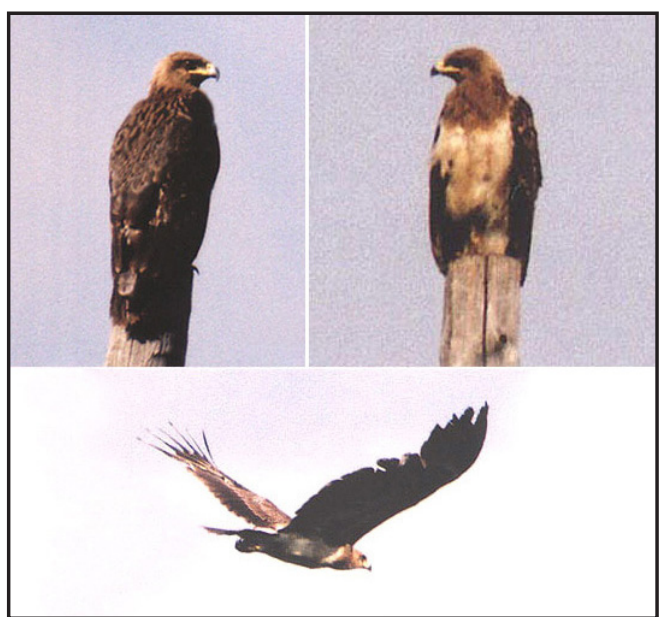

of pale morph in breeding habitat of GSE. In this article we want to close this gap.

Among 27 known breeding territories of GSE in Altai-Sayan Ecoregion only two (7.4 $\%)$ occupied by a couple in which one or both mates belong to var. fulvescens on different stages of post-juvenial moulting. Both nests situated in Minusinskaya depression. From 2000, in Altai-Sayan Ecoregion 44 observations of GSE were recorded, only $15.9 \%(n=7)$ of them related to fulvescens morph. All seven birds were observed in Minusinsk depression. Unfortunately, we never had a chance to check the nests with nestlings in first juvenile plumage in this region. Thus, we do not have a reliable data on frequency of this morph in broods of GSE, including ones procreated by pairs where one or both parents belong to var. fulvescens.

The next area where var. fulvescens of GSE occurs are Kulunda and Baraba plains that lie within the borders of Novosibirsk and Altai Regions in the eastern part of West Siberia. From 2003 to 2014, we have revealed 157 breeding territories of GSE in this area (127 in Altai Region and 30 in Novosibirsk Region), with only five (3.2\%) occupied by birds of palest morph. All five situated in Altai Region. From the total number of GSE observations in the area $(n=461)$ only $2.4 \%(n=11)$ of them related to fulvescens morph. Eight of them were recorded in Altai Region $(2.0 \%, n=401)$ and 3 in Novosibirsk Region (5 \%, n=60). Among 79 nestlings in first juvenile plumage observed by our team only 1 was var. fulvescens.

Рис. 1. Регистрации светлых больших подорликов (Aquila clanga m. fulvescens) в Южной Сибири: 1 - птицы в гнездящихся парах, 2 - птенец в гнезде, 3 - сиётки и молодые первого года жизни.

Fig. 1. Observations of the palest morph of the Greater Spotted Eagle (Aquila clanga m. fulvescens) in the Southern Siberia: 1 - birds in breeding pairs, 2 - nestling in nest, 3 - juveniles and subadult birds. 

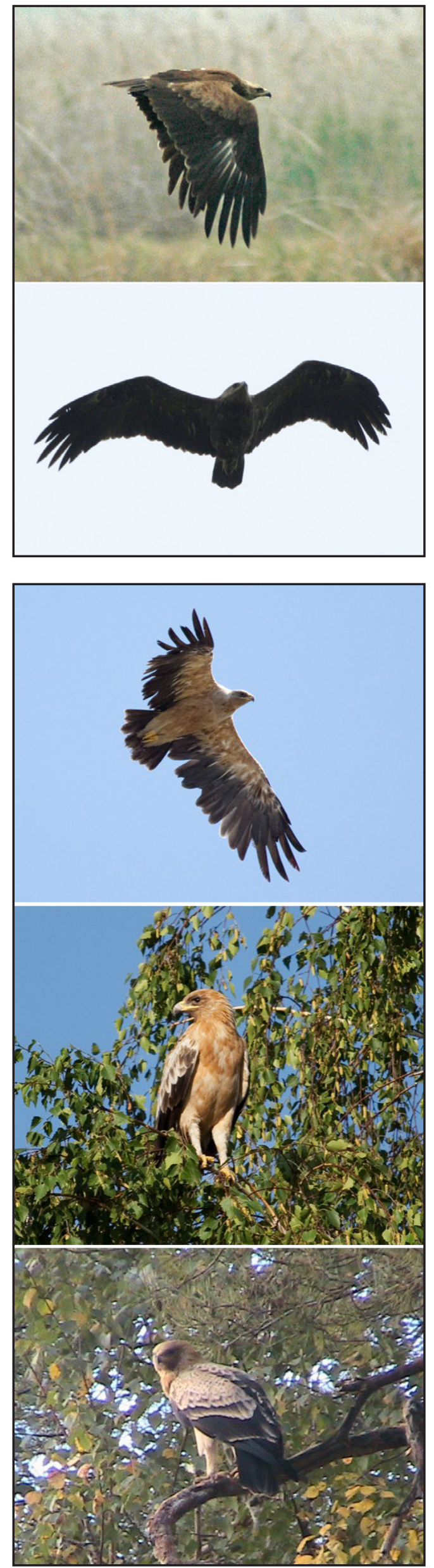

Большой подорлик светлой морфы на завершаюших стаАиях пост-Ювенимьной Аиньки: 22 июля 2012 г. (вверху) и 16 июля 2013 г. (внизу). Фото И. Карякина и К. Бартошука.

Final stages of post-juvenile moult in Greater Spotted Eagle fulvescens morph: 22/07/2012 (upper) and 16/07/2013 (bottom).

Photos by I. Karyakin and K. Bartozuk.

птица - в верховьях р. Баит (Красноярский край) 29 мая 2005 г. (Карякин, 2005; 2008). Пара птиц, одна из которых была светлой, 2 июля 2011 г. парила над известным участком в Аолине Белого Июса.

Из 27 гнездовых участков, известных в Алтае-Саянском регионе в пределах республик Алтай, Хакасия, Тува, Красноярского края и Кемеровской области, только на двух участках в Минусинской котловине (7,4 \%) установлено размножение светлых птиц на различных стадиях пост-ювенильной миньки. Из всей совокупности регистраций больших подорликов в регионе $(n=44) 7$ приходится на светлых птиц (15,9 \%) - все в Минусинской котловине. К сожалению, здесь нам ни разу не удамось проверить гнёзда больших подорликов с птенцами в полном гнездовом наряде, поэтому мы не располагаем статистикой по частоте встречаемости птенцов морсы fulvescens в выводках, в том числе и в парах с родителями, относяшимися к этой морсее.

Второй район встречаемости светлых подорликов - это Кулундинская и Барабинская равнины на востоке Западной Сибири в пределах Аитайского края и Новосибирской области. Явно прошлогодний fulvescens наблюдаися близ занятого гнезда пары типичных подорликов в районе с. Аяпуново Угловского р-на А^тайского края 9 июля 2003 г. Ешё один молодой светлый подорлик в паре с обычной птицей встречен 13 июля 2003 г. близ с. Волчиха Алтайского края. Подорлики морсы fulvescens в разной стадии пост-ювенильной миньки встречены в размножаюшихся парах на оз. Горькое Егорьевского р-на Алтай-

Молодые большие подорлики светлой морфы в Новосибирской области близ Купино 25 августа 2013 г. (вверху и в центре) и в Кисиухинском заказнике Алтайского края 15 августа 2012 г. (внизу). Фото С. Писаревского и С. Байдукова.

Juveniles of the Greater Spotted Eagle fulvescens morph in Novosibirsk region near Kupino village, 25/08/2013 (upper and center) and in Kisluhinskiy Nature Reserve, Altai Region, 15/08/2012 (bottom). Photos by S. Pisarevskiy and S. Baydukov. 


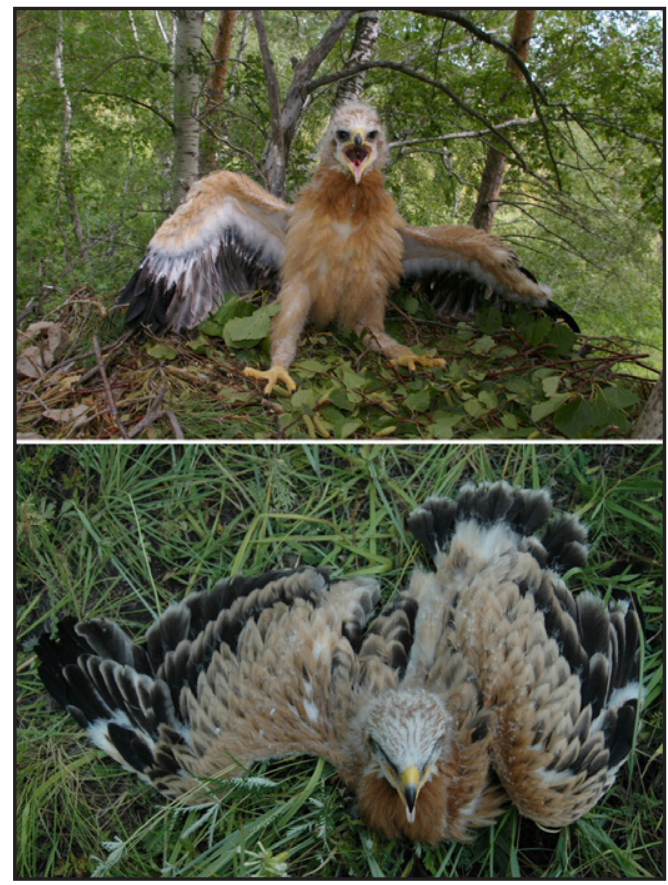

ского края 22 мая 2005 г., в Мамонтовском заказнике 22 июля 2009 г. и близ оз. Горькое Романовского р-на Алтайского края 25 июля 2009 г. Молодой светлый подорлик, меняюший ювенильный наряд, встречен 1 августа 2011 г. на гнездовом участке близ с. Подстепное А^тайского края. Эта же птица повторно встречена на Аанном участке 22 июля 2012 г. ${ }^{23}$ и 16 июля 2013 г. ${ }^{24} \mathrm{~B}$ 2013 г. от типичного большого подормика птицу отличала ^ишь более светлая голова. Молодой fulvescens встречен 15 августа 2012 г. в Кислухинском заказнике Алтайского края ${ }^{25}$ (в 2014 г. зАесь найдено гнездо подорликов, в котором птенец был типичной окраски). И, наконец, 20 июля 2013 г. у пары типичных подорликов в гнезде близ Кормихи обнаружен птенец fulvescens ${ }^{26}$. Этот птенец вывелся у пары, которая наблюдаАась в течение трёх гнездовых сезонов, причём в течение $\Delta$ вух сезонов у неё наблюдались птенцы обычной морфы. В Новосибирской области светлые поАорлики наблюдались 25 августа 2013 г. близ Купино, в 8 км Аруг от Аруга 27,28 и близ Троицкого Карасукского р-на 24 сентября 2014 г. ${ }^{29}$
Птенец большого подорлика морфы fulvescens. Алтайский край, 20 июля 2013 г. Фото Э. Николенко и И. Карякина.

Nestling of the Greater Spotted Eagle fulvescens morph. Altai Region, 20/07/2013. Photos by E. Nikolenko and I. Karyakin.

Таким образом, на востоке Западной Сибири, в пределах Алтайского края и Новосибирской области, за период исследований с 2003 по 2014 гг. выявлено 157 гнездовых участков больших подормиков (127 - в Аитайском крае и 30 - в Новосибирской области), на пяти из которых встречены светлые птицы (3,2 \%). Все встречи гнездяшихся или вероятно гнездяшихся светлых птиц произошли в Алтайском крае (3,9 \% от обшего числа встреч птиц на гнездовых участках в Алтайском крае). Из всей совокупности регистраций больших подорликов в регионе $(n=461) 11$ приходится на светлых птиц (2,4\%): 8 - в Аитайском крае $(2,0 \%, n=401)$ и 3 - в Новосибирской области (5\%, n=60). Из 79 птенцов, осмотренных в гнездовом наряsе, мишь 1 (1,3\%) оказался fulvescens.

Авторы благодарят всех участников полевых работ и мониторинга большого подорлика в Южной Сибири, особенно С. Бакку, К. Бартошука, М. Грабовского, ^. Зиневич, М. Кожевникова, Р. Аапшина, А. Панжину, А. Семёнова.

\section{Митература}

$\triangle$ ементьев Г. П. Отряд хишные птицы. Птицы Советского Союза. Т. 1. М., 1951. С. 70-341.

Карякин И.В. Встречи редких орлов в Южной Сибири. - Пернатые хишники и их охрана. 2005. № 4. С. 64-67.

Карякин И.В. Особенности экологии большого подорлика в Запацной Сибири. - Изучение и охрана большого и малого подорликов в Северной Евразии: Материалы V международной конференции по хишным птицам Северной Евразии, Иваново, 4-7 ревраля 2008 г. Иваново, 2008. C. 153-164.

Штегман Б.К. Фауна СССР. Птицы. Том I, Вып.5. Аневные хишники. М., 1938. 168 с.

Forsman $D$. The Raptors of Europe and the Middle East. A Handbook of Field Identification. London: Christopher Helm, 1999. 589 p.

\footnotetext{
23 http://raptors.wildlifemonitoring.ru/\#object/o_id=2419

24 http://raptors.wildlifemonitoring.ru/\#object/o_id=1637

25 http://raptors. wildlifemonitoring.ru/\#object/o_id=25384

26 http://raptors. wildlifemonitoring.ru/\#object/o id $=1649$

27 http://raptors. wildlifemonitoring.ru/\#object/o_id $=4090$

28 http://raptors. wildlifemonitoring.ru/\#object/o_id $=4092$

29 http://raptors.wildlifemonitoring.ru/\#object/o_id=19699
} 